\title{
Gamma Ray Irradiation Effects on the Mechanical and Chemical Properties of $\mathrm{CuO}-\mathrm{Bi}_{2} \mathrm{O}_{3}-\mathrm{SiO}_{2}$ Glasses
}

\author{
H. A. Saudi \\ Department of Physics, Faculty of Science (Girls' Branch), Al-Azhar University, Nasr City, Egypt
}

Email address:

heba_saudi@yahoo.com

To cite this article:

H. A. Saudi. Gamma Ray Irradiation Effects on the Mechanical and Chemical Properties of $\mathrm{CuO}-\mathrm{Bi}_{2} \mathrm{O}_{3}-\mathrm{SiO}_{2}$ Glasses. American Journal of Physics and Applications. Vol. 4, No. 6, 2016, pp. 140-144. doi: 10.11648/j.ajpa.20160406.11

Received: October 31, 2016; Accepted: December 1, 2016; Published: December 17, 2016

\begin{abstract}
The effect of gamma radiation on the mechanical and chemical properties of $\mathrm{x} \mathrm{CuO},(70-\mathrm{x}) \mathrm{Bi}_{2} \mathrm{O}_{3}, 20 \mathrm{SiO}_{2}, 10 \mathrm{Na}_{2} \mathrm{O}$, where $0 \leq \mathrm{x} \leq 30$ weight $\%$ were carefully studied in order to obtain information about the changes that appear in the structure of the glass matrix with the doping of copper ions. The glass matrix was fabricated by melt-quenching technique. The results showed that, the glass system has good durability, density and mechanical properties with increasing $\mathrm{CuO}$ content at the expense of $\mathrm{Bi}_{2} \mathrm{O}_{3}$, and that the effect of irradiation with gamma dose is very small. UV-VIS absorption spectra for all glasses have a single asymmetric band, which corresponds to a $\mathrm{BiO}_{3} \rightarrow \mathrm{BiO}_{6}$ transition of the $\mathrm{Cu}^{2+}$ ions in octahedral symmetry with an elongated tetragonal distortion. These measurements indicate the presence of $\mathrm{Cu}^{2+}$ ions in the glasses. Furthermore, it has good water resistance ability with increasing copper oxide. So, it can be used as a container for keeping radioactive waste and radioactive sources.
\end{abstract}

Keywords: Bismosilicate Glasses, Hardness, Durability

\section{Introduction}

During recent years, a large number of studies have been concentrated on various types of glasses to evaluate their behavior under different irradiation conditions. The treatment and disposal of the radioactive wastes are increasingly becoming a major operating expense to nuclear power plants. Size reduction is becoming one of the most important issues of radioactive waste management around the world, because the cost of waste storage and disposal. The interactions of nuclear radiation, such as gamma rays with glass containing transition metals like $\mathrm{Cu}$ and $\mathrm{Bi}$ heavy metals are very important from a scientific point of view. Such interactions cause noticeable changes in the structure and chemical properties of glasses [15]. It was found that these changes depend not only on the type of radiation and dose, but also on glass type and composition [5]. The damage caused by radiation depends on the type and energy of the radiation, as well as the total dose.

The mechanical properties of nuclear waste form glasses are important, as they will determine the degree of cracking that may occur either on cooling or at accident handling. In a radioactive glass block that is subject to radiogenic heating, stresses are maintained due to a temperature gradient between the core and the surface. This gradient decreases with time, but persists over hundreds of years until ${ }^{137} \mathrm{Cs}$ and ${ }^{90} \mathrm{Sr}$ have decayed. Surface hardness measurements quantify the resistance of glass sample to both plastic and elastic deformation [6].

$\mathrm{Bi}_{2} \mathrm{O}_{3}$ participate in the glass structure with two coordination as network former in the form of $\mathrm{BiO}_{3}$ (pyramidal) and as network modifier such as $\mathrm{BiO}_{6}$ (octahedral) units [7-8]. Bismuth ion was reported as an efficient luminescent activator [9]. $\mathrm{SiO}_{2}$ is one of the most common glass former and is present in almost all important commercially glasses. The silicate glasses are used as well to shield material of IR radiation. The introduction of transition-metal oxide, $\mathrm{CuO}$ in the glass matrix changes the structure of glasses, where the metal oxide is acting as a modifier and can determine semiconducting properties of the glasses [10]. Alkali metal ions $\mathrm{Na}^{+}$are added to a glass matrix to bring down the melt temperature during the manufacturing process, since sodium is known to be relatively mobile at low temperatures in silicate glasses. But the presence of higher concentration of $\mathrm{Na}^{+}$ions in glasses decreased the surface resistance to aqueous attack.

In the present work study on the mechanical, density and chemical properties of the glass system bismuth silicate glasses based on the $\mathrm{Na}_{2} \mathrm{O}-\mathrm{Bi}_{2} \mathrm{O}_{3}-\mathrm{CuO}-\mathrm{SiO}_{2}$ system with varying compositions to have been performed examining their suitability for nuclear shielding purposes as well as in 
radiation dosimetry applications.

\section{Experimental}

Analytically pure grade chemicals were used to prepare the following glass system: x CuO, (70-x) $\mathrm{Bi}_{2} \mathrm{O}_{3}, 20 \mathrm{SiO}_{2}, 10 \mathrm{Na}_{2} \mathrm{O}$; where $0 \leq \mathrm{x} \leq 30$ weight $\%$, which was prepared by melt quenching technique at $1100^{\circ} \mathrm{C}$ for two hours and then annealed in a separate annealing furnace at $250^{\circ} \mathrm{C}$ and then slowly cooled to the room temperature to remove any internal stresses. Glass density measurements were measured at room temperature using the standard Archimedes method, with toluene as the immersion fluid of stable density $\left(0.866 \mathrm{gm} / \mathrm{cm}^{3}\right)$.

A Vicker's diamond indenture was used in a standard microhardness tester (Leco AMH 100, USA) for specimen indentation. A load of (25-200) gm applied for $15 \mathrm{~s}$ was used to make indentations in specimens of glasses. The microhardness was measured using polished samples of the glasses under investigation in the form of plates $(4 \mathrm{~mm})$ thick. Each sample was subjected to ten indentations at randomly selected areas; hence, errors in the measured values corresponding to the standard deviation were found to be about $2 \%$. The diagonal length impressions were measured and the hard-ness number $H$ was calculated according to a standard formula: $H=1.854 \mathrm{P} / \mathrm{d}^{2} \mathrm{~kg} / \mathrm{mm}^{2}$ [6], where $\mathrm{P}$ is the indentation load, and $\mathrm{d}$ is the diagonal length impression.

The chemical durability of glasses was determined by measuring the dissolution rates from the calculated weight loss of the samples immersed in distilled water. For these measurements, the specimens have a circular form with a diameter of approximately $1 \mathrm{~cm}$. The samples were polished, dried and weighted before suspending them in $100 \mathrm{ml}$ distilled water. The beaker was placed in an oven at $90^{\circ} \mathrm{C}$. The specimens were weighted at the end of 15, 30 and 60 days. The dissolution rate (DR) was calculated from the measured weight loss $(\Delta w)$ using the equation $\mathrm{DR}=\mathrm{DW}$ (gm)/ A $\left(\mathrm{cm}^{2}\right) * \mathrm{t}$ (day) where $A$ is the surface area of the sample and $t$ is the immersion time [6].

UV-VIS optical spectra of glass samples of equal thickness were recorded at room temperature using a spectrophotometer (JASCO Corp., V-570, UV/VIS/NIR) to record transmittance (T). The resolution limit of the spectrophotometer is equal to $0.5 \mathrm{~nm}$. The accuracy of measuring transmittance is \pm 0.002 in the range (190-1500) $\mathrm{nm}$.

Optical spectra over a wide range of photon energy is very useful technique for understanding the basic mechanism of optically-induced transitions in crystalline and amorphous materials, as well as providing information about the band structure.

${ }^{137} \mathrm{Cs}$ gamma cell $(1500 \mathrm{Ci})$ was used as a $\gamma$-ray source with a dose rate of 10 and $20 \mathrm{KGy} / \mathrm{s}$, at room temperature $\left(30^{\circ} \mathrm{C}\right)$.

\section{Results and Discussion}

\subsection{Density}

The density is a powerful tool capable of exploring the changes in the structure of glasses. The density values decrease with the increase in $\mathrm{CuO}$ content. This data are expected in relation to the low molecular weight of transition metal $\mathrm{Cu}$ cation replacement of high molecular weight $\mathrm{Bi}_{2} \mathrm{O}_{3}$. Bismuth oxide can enter the structure as a network modifier and or a network former depending on the composition of glass, it is assumed that $\mathrm{BiO}_{3}$ can participate as a former and $\mathrm{BiO}_{6}$ as a modifier in interstitial positions, also $\mathrm{CuO}$ can participate as $\mathrm{Cu}^{++}$in interstitial position

Irradiation with $\gamma$-rays are assumed to create displacements, electronic defects and/or breaks in the network bonds, which allow the structure to relax and fill the relatively large interstices that exist in the interconnected network of silicon and oxygen atoms causing expansion followed by compaction of the volume $[11,12]$.

The slight change in density may be due to the possible atomic displacements that result from $\gamma$-collision with the glass, which may materially alter the stresses in the glass.

Table 1. Effect of gamma irradiation on glass density in $\mathrm{gm}^{\mathrm{cm}}{ }^{-3}$.

\begin{tabular}{llll}
\hline \multirow{2}{*}{$\mathbf{X}(\mathbf{w t} \%)$} & $\begin{array}{l}\boldsymbol{\rho} \text { before } \\
\text { irradiation }\end{array}$ & \multicolumn{2}{c}{$\boldsymbol{\rho}$ after irradiation } \\
\cline { 3 - 4 } & 5.696 & 5.716 & $\mathbf{1 0} \mathbf{~ G y} / \mathbf{s}$ \\
\hline 0 & 5.660 & 5.699 & 5.728 \\
5 & 5.642 & 5.661 & 5.702 \\
10 & 5.614 & 5.632 & 5.685 \\
15 & 5.587 & 5.597 & 5.653 \\
20 & 5.561 & 5.580 & 5.599 \\
25 & 5.533 & 5.567 & 5.586 \\
30 & & & 5.569 \\
\hline
\end{tabular}

As shown in table 1 and figure 1 the densities of all the studied glass have the same trend where the density slightly increases with irradiation. The glass containing no cupper, density is the most affected by irradiation, where its density shows a remarkable increase. The densities of the glasses increase with the increase of irradiation dose, which is represented, by increasing of the exposure time to the irradiation source. This result is due to a tightening effect or compaction of the glass structure. Also the change in the glass density can be attributed to the absorption of the $\gamma$ in the glass. The transition metals present in the glass can change its coordination and prevent the radiation from attacking the glass center. However, it will not completely return to the equilibrium density.

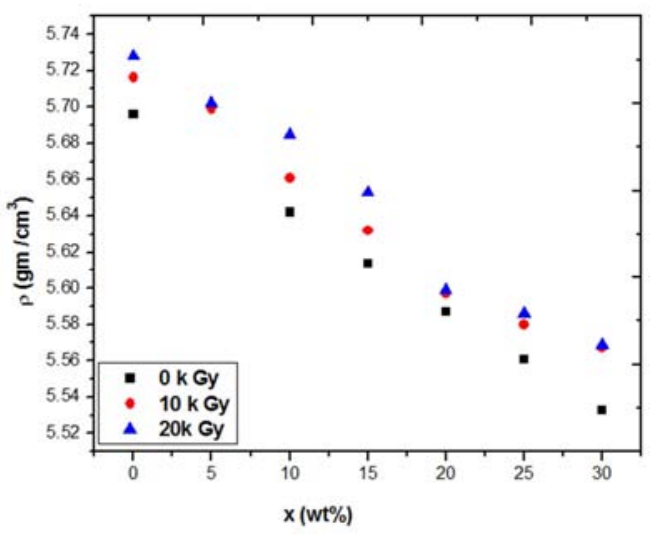

Figure 1. Effect of gamma irradiation on glass density in $\mathrm{gm}^{\mathrm{cm}}{ }^{-3}$. 


\subsection{Microhardness}

Hardness may be defined as the resistance of a material to surface indentation or penetration. The variation of the hardness number $\left(H_{v}\right)$ with load from 0 to 200 gm for glass samples is illustrated in table 2 and figure 2. It is evident from the figure that have increased with load up $50 \mathrm{gm}$, beyond this load $\left(H_{v}\right)$ have tended to be saturated. Furthermore the micro hardness of glass samples increases with increasing $\mathrm{CuO}$ content. So, the addition of $\mathrm{CuO}$ strengthened the bond energy between $\mathrm{Bi}-\mathrm{O}$ and $\mathrm{Si}-\mathrm{O}$, and that may rise to the surface of this glass, which relates in turn to the increase in the microhardness results which depend on the surface structure. The increase in hardness number $\left(H_{v}\right)$ with increasing load can be attributed strain hardening phenomena [13]. This can be understood considering that glass density changes depend on the ions housed in the network, but microhardness depends only on the surface structure. On applying load, the glass samples are subjected to some strain hardening and when $\mathrm{H}_{\mathrm{v}}$ becomes constant after $50 \mathrm{gm}$. The glass is completely, strain hardening. The rate of strain hardening is great at low load and lower at higher load. These results density and microhardness show that the glass containing $\mathrm{CuO}$ has the lowerer density and higher microhardness because microhardness involve the creation of a compression when the indenter is pushed downwards into the glass with an applied load. After the removal of the indenter, it is obvious that in addition to the recoverable elastic compression experienced by the sample, some material in the neighborhood of the indenter could not have been displaced [14].

Table 2. Variation of $H_{v}$ with load for glass samples.

\begin{tabular}{lllll}
\hline $\mathbf{X}(\mathbf{w t} \%)$ & $\mathbf{2 5} \mathbf{g m}$ & $\mathbf{5 0} \mathbf{g m}$ & $\mathbf{1 0 0} \mathbf{g m}$ & $\mathbf{2 0 0} \mathbf{g m}$ \\
\hline 0 & 6859.54 & 6903.62 & 6909.62 & 6909.62 \\
5 & 7371.25 & 7421.47 & 7423.47 & 7423.47 \\
10 & 7686.27 & 7730.39 & 7732.39 & 7732.39 \\
15 & 8129.39 & 8182.48 & 8184.48 & 8184.48 \\
20 & 8494.567 & 8542.82 & 8541.82 & 8541.82 \\
25 & 8701.62 & 8749.64 & 8749.64 & 8749.64 \\
30 & 9404.35 & 9453.55 & 9453.55 & 9453.55 \\
\hline
\end{tabular}

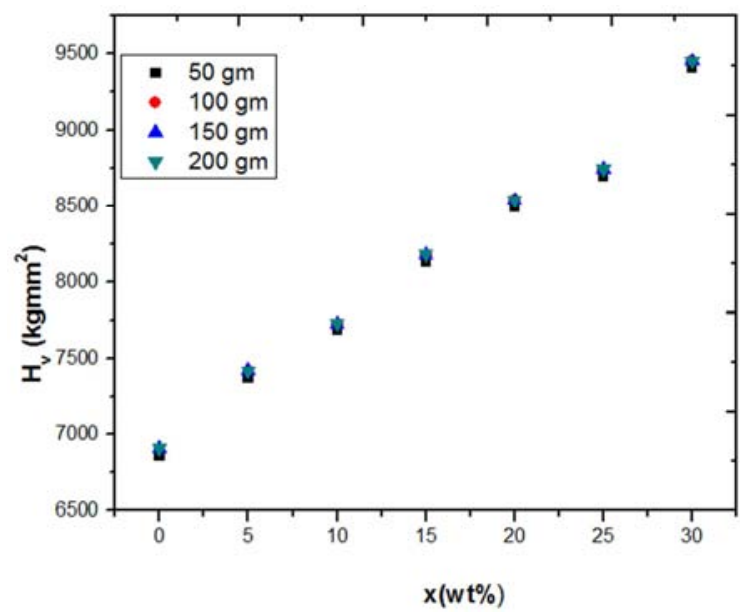

Figure 2. Variation of $H_{v}$ with different load for glass samples.

\subsection{The Effect of Gamma Irradiation on Micro Hardness}

Table 3 and figure 3 illustrate the micro hardness of the prepared glasses after gamma irradiation with two specific gamma doses $(10,20 \mathrm{KGy} / \mathrm{s})$ at load $=100 \mathrm{gm}$. This load was chosen as most optimum in the range 25-200 gm, for which it was possible to produce good quality indentations and the microhardness did not depend on the applied load. The micro hardness decreases slightly with doses as compared with original samples; this means that the effect of gamma irradiation on glasses can be verified as a result from almost purely electronic processes [15, 16 and 17]. The close agreement observed for all the glass compositions suggests that the hardness variations resulting from irradiation could be attributable mainly to their common sodium bismuth silicate glass formulation. This study allows correlating changes in the macroscopic properties observed under irradiation with structural evaluations.

These effects of irradiation occur because electrons are excited and leave their positions and travel through the glass network. The addition or removal of one or more electrons from intrinsic defects or impurity ions results in the formation of induced color.

The glass with increasing $\mathrm{CuO}$ content has a slight decrease of the micro hardness which is assumed to be due to trace $\mathrm{Cu}^{+2}$ ions present as impurities

Table 3. Variation of $H_{v}$ with different $\gamma$ ray doses for glass samples at $100 \mathrm{gm}$.

\begin{tabular}{lll}
\hline $\mathbf{X}(\mathbf{w t} \%)$ & $\mathbf{1 0 ~ K G y / s}$ & $\mathbf{2 0 ~ K G y / s}$ \\
\hline 0 & 6808.42 & 6799.62 \\
5 & 7322.37 & 7317.47 \\
10 & 7631.59 & 7623.39 \\
15 & 8083.48 & 8074.48 \\
20 & 8440.72 & 8438.82 \\
25 & 8647.68 & 8641.64 \\
30 & 9351.65 & 9344.55 \\
\hline
\end{tabular}

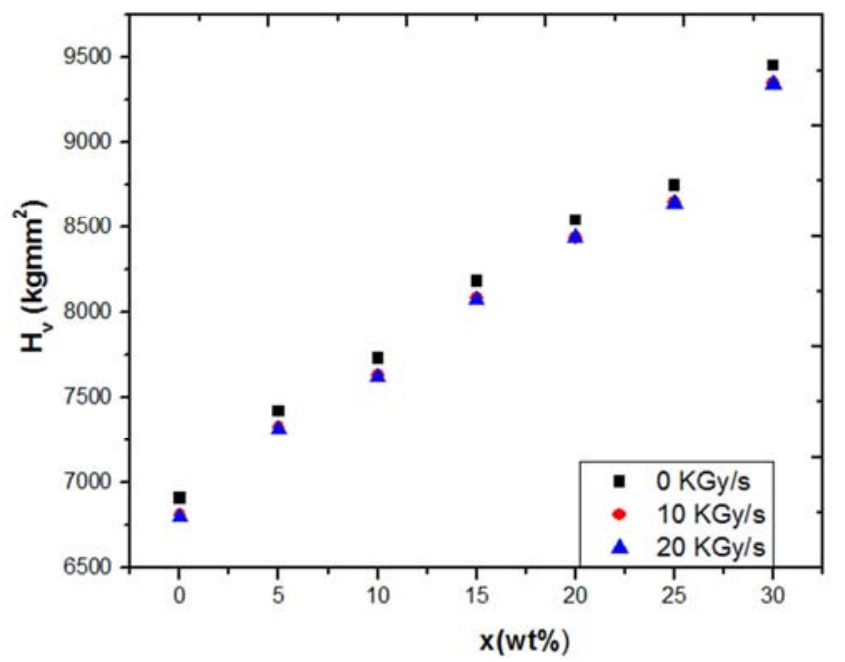

Figure 3. Variation of $H_{v}$ with different $\gamma$ ray doses for glass samples at $100 \mathrm{gm}$.

\subsection{Chemical Durability Before and After Irradiation}

The presence of copper in the prepared glasses causes an enhancement in the internal network glass structure and also 
a change in the action of the attacking water. Table 4 indicates that dissolution rates $D_{R}$ tends to decrease with increasing $\mathrm{CuO}$. $\mathrm{D}_{\mathrm{R}}$ decreases from $10^{-4}$ to $10^{-7} \mathrm{gm} \mathrm{cm}^{-2} \mathrm{~min}^{-1}$. Low $\mathrm{D}_{\mathrm{R}}$ means that the glass has a high chemical durability. With increasing $\mathrm{CuO}$ content in glass system found that the glass is to be more chemical, durable in water because the higher content of $\mathrm{CuO}$ the higher chemical durability. It can be observed that $\mathrm{CuO}$ addition together with $\mathrm{Bi}_{2} \mathrm{O}_{3}$ improved the durability more than $\mathrm{Bi}_{2} \mathrm{O}_{3}$ alone. Also from table 4 , it can be observed that there is no significant change in $D_{R}$ with increasing the immersions periods. The $D_{R}$ values after irradiation are less decease with increasing doses, so these glass samples can be considered as chemical durable glass. Gamma irradiation effects on interstitial compounds $[6,18]$ while the heavy ions $\mathrm{Bi}^{+3}$ and main silicate network groups remain and resist irradiation. On the other hand, this glass is a resistance to each of corrosion as well as radiation effects. This result is in agreement with the density results which show an increase in the corrosion during irradiation. This increase in corrosion left compacting and voids in the glass structure, which in turn results, decrease in the volume affecting the observed increase in density.

Table 4. Variation of dissolution rates $D R$ with different immersion period and different doses.

\begin{tabular}{|c|c|c|c|c|c|c|c|c|c|}
\hline Time & 15 days & & & 30 days & & & 60 days & & \\
\hline$X(w t \%)$ & Dr (0 KGy/s) & Dr (10 KGy/s) & Dr (20 KGy/s) & Dr (0 KGy/s) & $\operatorname{Dr}(10 \mathrm{KGy} / \mathrm{s})$ & Dr (20 KGy/s) & Dr $(20 \mathrm{KGy} / \mathrm{s})$ & Dr (10 KGy/s) & Dr (20 KGy/s) \\
\hline 0 & $9.2 * 10^{-6}$ & $9.1 * 10^{-6}$ & $9.1 * 10^{-6}$ & $9.4 * 10^{-6}$ & $9.2 * 10^{-6}$ & $9.1 * 10^{-6}$ & $9.8 * 10^{-6}$ & $9.4 * 10^{-6}$ & $9.1 * 10^{-6}$ \\
\hline 5 & $8.4 * 10^{-6}$ & $8.3 * 10^{-6}$ & $8.2 * 10^{-6}$ & $8.1 * 10^{-6}$ & $8.010^{-6}$ & $7.9 * 10^{-6}$ & $7.8 * 10^{-7}$ & $7.3 * 10^{-7}$ & $7.1 * 10^{-7}$ \\
\hline 10 & $6.7 * 10^{-6}$ & $6.5 * 10^{-6}$ & $6.3 * 10^{-6}$ & $6.2 * 10^{-6}$ & $6.1 * 10^{-6}$ & $6.1 * 10^{-6}$ & $6.0 * 10^{-7}$ & $5.8^{*} 10^{-7}$ & $5.8 * 10^{-7}$ \\
\hline 15 & $6.11 * 10^{-6}$ & $6.1 * 10^{-6}$ & $5.9 * 10^{-6}$ & $5.9^{*} 10^{-6}$ & $5.8 * 10^{-6}$ & $5.7 * 10^{-6}$ & $5.7 * 10^{-7}$ & $5.5 * 10^{-7}$ & $5.4 * 10^{-7}$ \\
\hline 20 & $5.8 * 10^{-6}$ & $5.7 * 10^{-6}$ & $5.6 * 10^{-6}$ & $5.6^{*} 10^{-6}$ & $5.5 * 10^{-6}$ & $5.4 * 10^{-6}$ & $5.3 * 10^{-7}$ & $5.2 * 10^{-7}$ & $5.1 * 10^{-7}$ \\
\hline 25 & $4.43 * 10^{-6}$ & $4.43 * 10^{-6}$ & $4.43 * 10^{-6}$ & $4.6 * 10^{-6}$ & $4.5 * 10^{-6}$ & $4.4 * 10^{-6}$ & $4.4 * 10^{-7}$ & $4.2 * 10^{-7}$ & $4.1 * 10^{-7}$ \\
\hline
\end{tabular}

\subsection{Effect of CuO on Optical Transmission Spectra}

Optical transmission spectra, as a function of $\mathrm{CuO}$ concentration at room temperature in the wavelength region 200-2600 $\mathrm{nm}$ is shown in Fig 4. Due to the homogeneous distribution of $\mathrm{CuO}$ in the prepared glass matrices, all glass samples are transparent. The optical transmission edge is not sharp and extended over a wide wavelength range, consistent with the amorphous nature of the prepared glasses. The wavelength at which the percentage transmission is zero is referred to cutoff wavelength $\left(\lambda_{c}\right)$. The $\lambda_{\mathrm{c}}$ slightly shifted to longer wavelength with increasing of $\mathrm{CuO}$ concentration. In Fig. 4 the range $400-600 \mathrm{~nm}$, it has been found the shoulder peaks around and $450 \mathrm{~nm}$ is attributed to $\mathrm{Bi}^{+3}$ ions. This shoulder, observed in all the samples is similar, The intensity increases with increasing the copper concentration. A strong band centered at $800 \mathrm{~nm}$, corresponding to the $\mathrm{BiO}_{3} \rightarrow \mathrm{BiO}_{6}$ transition $[19,20]$. The This broadband can be identified as the $\mathrm{d}-\mathrm{d}$ transitions due to $\mathrm{Cu}^{2+}$ ions and described in terms of the ligand field theory [19].

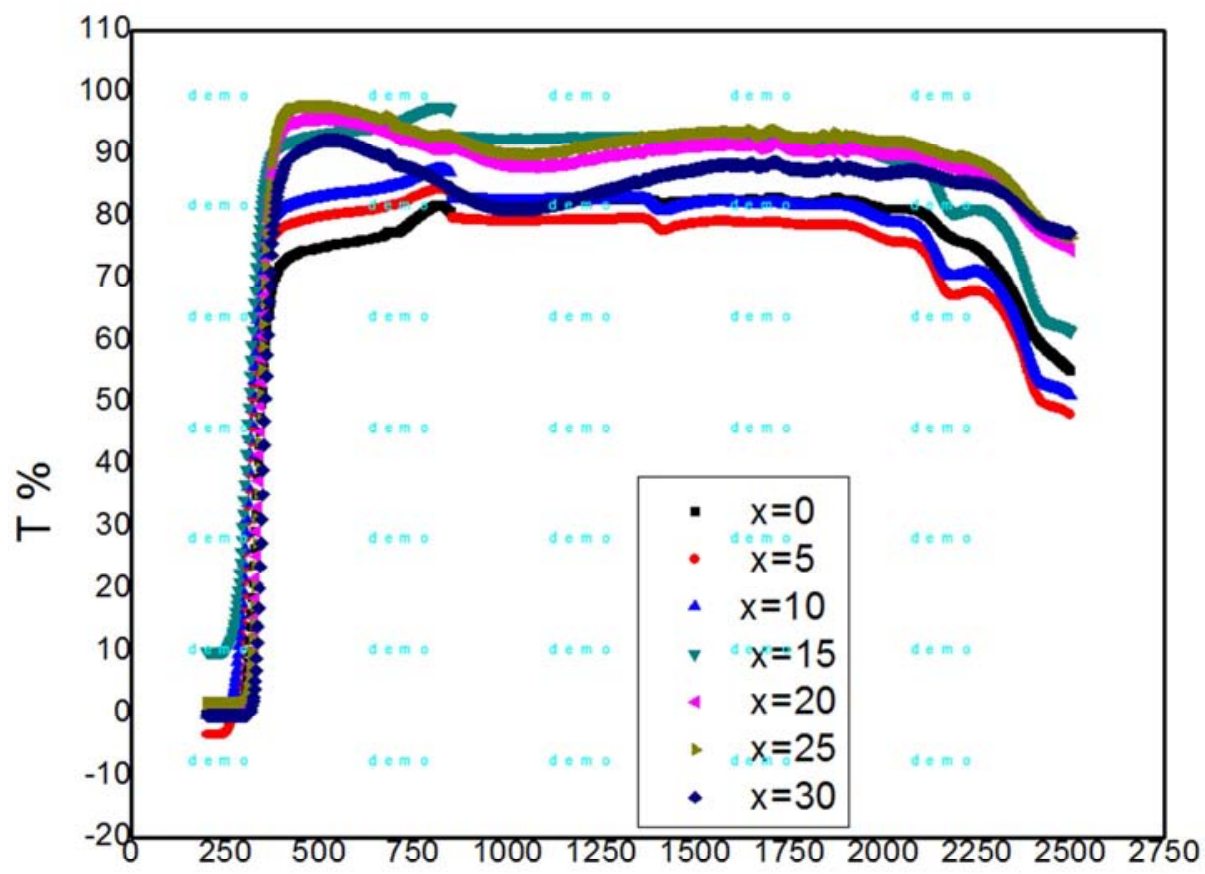

Wavelength $(\mathrm{nm})$

Figure 4. The optical transmission for all composition of all glass samples. 


\section{Conclusion}

The density of bismuth silicate glass showed that the lowest density of the studied glasses is given by glass containing $30 \% \mathrm{CuO}$ where the presence of $\mathrm{CuO}$ in the glass causing an increase in the $\mathrm{BiO}_{3}$ units because it consume some of the available $\mathrm{O}_{2}$ in $\mathrm{Na}_{2} \mathrm{O}$ which are required to convert $\mathrm{BiO}_{3}$ to $\mathrm{BiO}_{6}$. The density increases for all of the studied glasses when subjected to irradiation, this may be due to the absorption of gamma in the glass surface causing a displacement of the ions. The microhardness did not depend on the applied load. The addition of copper ions in the glasses determines the increasing of the intensity of the optical transmission band Also the glass containing $\mathrm{CuO}$ is the most affected glass when subjected to irradiation, where it gives the highest rate of increase either in density or hardness values. This can be attributed to the large size of $\mathrm{CuO}$ and $\mathrm{Bi}_{2} \mathrm{O}_{3}$, which causes an expansion of the glass volume. The same results were achieved form measuring dissolution rate, which lower the average coordination number of oxygen, however, these large configurations resulted in a compaction of the surrounding structure.

Generally bismuth silicate glasses containing copper oxide have high hardness and large resistance to deformation due to irradiation induced defect. The present investigated glass has good water resistance ability with increasing copper oxide. So, it can be used as a container for keeping radioactive waste and radioactive sources.

\section{References}

[1] Y. B. Dimitriev, in Proc. Inter. Cong. Glass, Invited Papers, Edinburgh, Scotland, vol. 1 p. 225, (2001).

[2] L. Baia, R. Stefan, W. Kiefer, J. Popp, S. I. Simon, J. NonCryst. Solids 303, 379 (2002).

[3] S. Sindhu, S. Sanghi, A. Agarwal, V. Seth, N. Kishore, Mater. Chem. Phys. 90, 83 (2005).
[4] F. H. ElBatal, Nucl. Instrum. Methods Phys. Res., Sect. B, Beam Interact. Mater. Atoms 254, 243 (2007).

[5] F. H. ElBatal, S. Y. Marzouk, N. Nada, S. M. Desouky, Physica B 391, 88 (2007).

[6] Heba A. Saudy, Sawsan El Mosallamy, Samir U. El Kameesy, Nashwa Sheta, Ahmed G. Mostafa, Hanaa A. Sallam, World Journal of Condensed Matter Physics, 3, 9-13 (2013). (http://www.scirp.org/journal/wjcmp).

[7] J. Fu, H. Yatsuda, Phys. Chem. Glasses 36 (1995) 211.

[8] L. Montagne, G. Palavit, G. Mairesse, M. Draoui, K. Aomari, M. Saidi Idrissi, Phys. Chem. Glasses 38 (1997) 15.

[9] Werner Vogel, Glass Chemistry, Second Edition SpringerVerlag, Berlin, 1994.

[10] I. Ardelean, solid state common 27,697, (1978).

[11] F. M. Ezz Eldin, N. A. El-Alaily, H. A. Elbatal, J. Radio-Anal. Nucl. Chem. 63 (2) (1992) 267.

[12] H. A. Saudi, Applied Mathematics and Physics, Vol. 1, No. 4, 143-146 (2013). (http://pubs.sciepub.com/amp/1/4/7 C Science and Education Publishing).

[13] R. Bajpai and S. C. Datt, Indian J pure Appl. Phys, 24 (1986).

[14] N. A. El-Alaily, W. M. Abdallah, B. A. Sabrah, A. I. Saad, Silicon (2017) 9: 117-130 DOI 10.1007/s12633-015-9330-7.

[15] E. J. Friebele, Radiation effects, in: D. R. Uhlmann, N. J. Kreidl (Eds.), Optical Properties (2012).

[16] A. Bishay, J. Non-Cryst. Solids 3 (1970) 54-114.

[17] M. A. Marzouk et al. / Journal of Non-Crystalline Solids 387 (2014) 155-160.

[18] LI Xiu-ying, YANG Hua-ming, REN Yu-xi, J. Cent. South Univ. (2013) 20: 44-49

[19] D. S. McClure, Solid State Physics, Vol. 9, Ed. F. Seitz, D. Turnbull, Academic Press, New York, 1959, p. 195.

[20] B. Karthikeyan, S. Mohan, Matt. Lett. 57, 3789 (2003). 